Laboratorio de Arte, 7-1994 http://dx.doi.org/10.12795/LA.1994.i07.03

\title{
FIESTAS SEVILLANAS DEL SIGLO XVI: Diversiones aristocráticas y regocijos populares
}

\author{
POR RAFAEL RAMOS SOSA
}

\begin{abstract}
Tras una investigación en los archivos de la ciudad, se trata de acercarnos a los motivos y funciones de las fiestas sevillanas de tradición medieval. Se describen brevemente los distintos festejos y se citan algunas de las ocasiones por las que se llevaron a cabo. Es un intento de profundizar en las razones del arraigo popular de estas celebraciones.
\end{abstract}

After our investigation in the archives of the city, we now will approach the motives and functions of the sevillian public festivities of medieval tradition. The different rejoicings will be described briefly, and some of the occasions will be mentioned wich caused them. It is an attempt to get to the bottom of the popular rooting these celebrations.

Burckhardt afirmó que para conocer la cultura de un pueblo es indispensable el estudio de la fiesta ${ }^{1}$. Este capítulo constituye uno de los más ricos y sustanciosos para todos los investigadores, especialmente para los historiadores del arte.

Se puede definir la fiesta como una manifestación en la que de forma extraordinaria y por un motivo especial, un pueblo, sociedad o grupo se reafirma en la conciencia de su existencia y en la voluntad de perseverar en su ser. El deseo de perpetuar el ser liga un ritual a los ciclos de la vida, de la muerte y de la renovación, que giran alrededor de las estaciones y del sucederse de las generaciones humanas ${ }^{2}$. El Cristianismo insertó esta realidad en la perspectiva de la historia de la salvación del hombre por Jesucristo, con la Redención como eje.

Sevilla en el siglo XVI es "puerto y puerta" de América. La bondad de su clima, el oro y la plata abundantes y la profunda fe religiosa de sus gentes, hará que sea la "ciudad festiva" por excelencia, la "ciudad soñada" ${ }^{3}$.

* Este trabajo fue presentado como ponencia en el Congreso Internacional Portugal and Spain of The Navigators. The Age of Exploration, The George Washington University. Washington, 13 al 16 de enero de 1992.

1. BURCKHARDT, Jacob, La Cultura del Renacimiento en Italia. Madrid, 1941, p. 254.

2. JACQUOT, Jean (ed), Les Fêtes de la Renaissance. París, 1973-1975, vol. III, p. 8.

3. PFANDL, Ludwig, Cultura y Costumbres del pueblo español de los siglos XVI y XVII. Introducción al estudio del Siglo de Oro. Barcelona, 1945, p. 221. 
El renacimiento aportó a las fiestas reales y religiosas un nuevo elemento: las arquitecturas efímeras con programas alegóricos y humanistas, que daban el tono monumental y erudito a la celebración ${ }^{4}$. Pero junto a la innovación seguirán vigentes y con fuerza los festejos tradicionales medievales protagonizados por la nobleza y pueblo. Vamos a hablar de estos regocijos populares y diversiones aristocráticas que hemos podido documentar en los archivos de la ciudad ${ }^{5}$. Son las fiestas de "toros y cañas", las justas y torneos, máscaras y carros alegóricos, el juego de "correr la seda", regatas en el río, batallas ficticias y naumaquias, luminarias y fuegos de artificio. En términos generales son los mismos para el resto de los reinos españoles contemporáneos ${ }^{6}$. Fueron la faz profana y el complemento de cualquier celebración. Su común denominador es el matiz emocional del júbilo y la alegría así como desarrollarse al aire libre, en el ámbito urbano, en las calles y plazas de la ciudad. En ellas participaban casi toda la sociedad de una u otra forma.

También podemos citar los saraos, comedias y justas literarias en círculos intelectuales y palaciegos. El teatro constituía otra de las pasiones del español, con un auge cada vez mayor y sin duda una de las claves para entender el Siglo de Oro ${ }^{7}$. Otras diversiones cotidianas eran el juego de cartas y dados, la tertulia, el cante y el baile espontáneo al alcance de todos. La danza es un elemento muy arraigado en el pueblo hispánico, indispensable en toda fiesta civil o religiosa.

\section{LOS MOTIVOS DE LA FIESTA}

En España "todo es motivo para la fiesta", exclama Defourneaux ${ }^{8}$. El calendario festivo religioso es cíclico, se asienta sobre el curso de las estaciones de la naturaleza, va al compás de sus transformaciones al mismo tiempo que la asume y eleva a un plano religioso superior. La vida de un andaluz se movía en

4. LLEO CAÑAL, Vicente, Nueva Roma: Mitología y Humanismo en el Renacimiento sevillano. Sevilla, 1979. También mi estudio "Fiestas reales sevillanas en el Imperio, 1500-1558", en Premios de Investigación Ciudad de Sevilla, 1986. Sevilla, 1988.

5. He trabajado en el Archivo Municipal de Sevilla, en las secciones $1^{a}, 3^{\mathrm{a}}, 10^{\mathrm{a}}, 13^{\mathrm{a}}, 15^{\mathrm{a}}$ y $17^{\mathrm{a}}$. En el Archivo de la Catedral de Sevilla, secciones de Actas Capitulares, Fábrica y Adventicios. Este trabajo fue mi Tesis de Licenciatura: Fiestas y Arquitecturas efímeras en la Sevilla del siglo XVI, 1500-1558; y un trabajo de investigación sobre el mismo tema en los años 1559-1599. También se puede ver ROMERO ABAO, Antonio del Rocío, y otros, Las fiestas de Sevilla en el siglo XV. Otros estudios. Madrid, Deimos, 1991.

6. BENNASSAR, Bartolome, Valladolid en el Siglo de Oro. Valladolid, 1983. MARSDEN, C.A., "Entrées et fêtes espagnoles au XVI siecle", en Les Fêtes de la Renaissance, vol. II, pp. 389-411. VAREY, J.E., "Les espectacles pyrotechniques en Espagne (XVI-XVII siecles)", en Les Fêtes..., vol. III, pp. 619-633.

7. MONTOTO, Santiago, Justas poéticas sevillanas del siglo XVI (1531-1542). Valencia, 1955. SENTAURENS, Jean, Seville et le thêatre. Burdeos, 1984.

8. DEFOURNEAUX, Marcellin, La vida cotidiana en la España de Siglo de Oro. Barcelona, 1983. BENNASSAR, Bartolomé, Los Españoles, Actitudes y Mentalidad. Madrid, 1985. 
definitiva entre dos estaciones: Invierno y Verano. El año litúrgico daba comienzo con el ciclo vital del Invierno. Traía consigo el Adviento, la Navidad, el Carnaval, la Cuaresma y la Semana Santa. Con el despertar de la vida y de la naturaleza comenzaba el ciclo del Verano con la Resurrección, Pascua Florida, el Corpus Christi -que fue la fiesta por antonomasia en la Sevilla y España de los siglos XVI y XVII- ${ }^{9}$, San Juan, Santa María de Agosto y un prolongado etcétera en los calurosos meses de septiembre y octubre. Este ritmo es inmutable y a la par que ofrece diversidad emocional, da una estabilidad vital al hombre. A estos períodos festivos litúrgicos hay que añadir los días de grandes festividades para todo el Cristianismo por santos y advocaciones diferentes. Además, las fiestas particulares de cada ciudad o reino, patronos como San Clemente, Santa Ana, Santas Justa y Rufina, en el caso sevillano. Por último se suman las fiestas eventuales como recibimientos de nuevos arzobispos y cardenales, reliquias, elección de un papa, etc.

Existe por otra parte -en realidad indisolublemente unido- el calendario festivo dinástico, político y civil. Se forja en los eventos de la familia real: nacimientos, defunciones, bodas, visitas regias, proclamaciones al trono; según las circunstancias y acontecimientos políticos como tratados de paz, victorias de guerra y sucesos de la vida civil ciudadana.

\section{TIPOS DE FESTEJOS}

Sin lugar a dudas el festejo más querido del pueblo español en todos sus estamentos es el de los toros. En las fiestas de toros los caballeros rejoneaban, lanceaban y mataban a los animales por honor, acompañados de sirvientes, peones y chulos. Estos últimos fueron los que poco a poco atrajeron la atención 'del público y nacieron así los toreros como tales, pero este fenómeno cuajó y se codificó en el siglo XVIII ${ }^{10}$. Los toros solían ser corridos a caballo por nobles y caballeros. A veces se recurría a mozos y jóvenes en cuadrillas contratadas en los pueblos de los alrededores de Sevilla. En el siglo XVI se extiende la afición y participación popular.

Hay que hacer un distingo muy interesante. En esta época, estas celebraciones eran "fiestas" de toros, no "corridas", como actualmente. La diferencia estriba en que en las "fiestas", los toros tenían un valor secundario, lo principal se encontraba en el motivo del festejo, todo lo demás era una manifestación expresiva y visible de la alegría por el acontecimiento. En cambio en la "corrida" se valora el espectáculo en sí.

9. LLEO CAÑAL, Vicente, Arte y espectáculo: la fiesta del Corpus Christi en Sevilla durante los siglos XVI y XVII. Sevilla, 1975. La obra citada de SENTAURENS es un estudio completo de la fiesta.

10. TORO BUIZA, Luis, Sevilla en la Historia del Toreo. Sevilla, 1947. COSSIO, José María de, Los Toros. Madrid, 1943. 
Los toros constituían un asunto conflictivo moralmente ya que peligraba la vida humana. A la reina Isabel la Católica no le gustaban y varios papas como Pío V, Gregorio XIII, Sixto V y Clemente VIII, los condenaron en mayor o menor medida sin lograr erradicarlos. Es conocida y significativa la respuesta de Felipe II a Sixto V en 1586. Le decía: "... que la bula no surtía sus efectos, por ser las corridas de toros una costumbre tan antigua que parecía estar en la sangre de los españoles, que no podían privarse de ella sin gran violencia... " $"$.

Normalmente los toros iban seguidos del "juego de las cañas", en el mismo lugar y sin solución de continuidad. El origen de este juego es árabe. Pedro Fernández de Andada escribió un libro titulado De la naturaleza del cavallo, (Sevilla, 1580) ${ }^{12}$. En el nos dice que lo primero que se debía hacer era señalar las cuadrillas, podían ser cuatro, seis y hasta ocho, y tener un buen caballo "porque en esto consiste la perfección del juego más que en la costa y curiosidad de las libreas". Antes de entrar en la plaza deben hacer un desfile por la ciudad para lucir las acémilas cargadas con las cañas y cubiertas con reposteros y brocados, seguidos de los caballeros con el diestro y su adarga. Después, los caballos donde los escuderos y pajes pondrán las lanzas con que los caballeros han de hacer la entrada. El desfile va acompañado de ministriles (músicos) tocando trompetas y tambores.

En la plaza se entraba según la costumbre del lugar. En Andalucía se hacía corriendo. Como es natural, lo que en un principio fue un enfrentamiento serio, con el curso de los siglos pasó a ser un juego, diversión y espectáculo. Ya en el siglo XVI se decía que todo esto tenía "mucho para las burlas y poco para las veras".

Las armas del juego fueron las lanzas (cañas) y adargas. Estas últimas son escudos lisos y rectos donde se pintaban las armas, motes y empresas de los señores. La liza comenzaba con el clamor de trompetas y clarines. Tras esta señal se abrían las puertas del recinto, entraban las cuadrillas y los padrinos de cada una. En el centro de la plaza, los padrinos simulaban un enfado y se retiraban. Un nuevo aviso y salían con las cañas para la lucha seguidos de las cuadrillas que tomaban posiciones. Cada una de colores diferentes.

Los caballeros comenzaban el enfrentamiento con una señal y la primera cuadrilla perseguía entre gritos a la primera del otro lado, esta a la siguiente y así sucesivamente hasta intervenir todas. Mientras, los lacayos y criados vestidos con ricas ropas salían y daban las cañas a los señores. De este modo comenzaba un ir y venir de dardos. Los sirvientes corrían de un lugar a otro para surtir de cañas a los caballeros, a veces sufrían caídas y revolcones con los que el público se divertía. Cuando todas las cuadrillas habían actuado se acababa la liza, arrojaban las armas al suelo y fingían la paz.

11. TORO BUIZA, L., o. c., p. 86.

12. TORO BUIZA, L., Noticias de los Juegos de Cañas Reales. Sevilla, 1944. Es la publicación de un manuscrito, de Pedro de Morales fechado en Sevilla en 1568. 
Otro de los festejos más tradicionales y persistentes fueron las justas y torneos. De honda raigambre medieval son exclusivos de nobles y caballeros, aunque el pueblo asistía al combate. La afición borgoñona por la fastuosidad y las fiestas caballerescas, llega a Castilla con Felipe el Hermoso y Carlos I. Se asoció con la tradición morisca hispánica de toros y cañas. Las justas son de origen francés y junto con el torneo son similares a las del resto de Europa ${ }^{13}$. Cuando decayó el ideal guerrero y caballeresco pasan a tener un sentido de diversión y deporte de la nobleza, momentos donde se exhibían las habilidades de los hombres linajudos, lucían sus armas, joyas y trajes costosos. En el medievo tuvieron un papel importante. El torneo es a juicio de Huizinga "el juego del amor romántico en su forma heroica..." ${ }^{14}$. En Sevilla las justas contaban con el apoyo legislativo de las Ordenanzas de la ciudad ${ }^{15}$. Estas celebraciones en los siglos XVI y XVII manifestaban la vigencia vigorosa de los ideales nobilarios y caballerescos medievales.

En la segunda mitad del siglo XVI aparece en Sevilla una nueva forma de festejo. Se trata de las máscaras que me parecen de origen italiano. Consisten en cuadrillas de personas que desfilaban vestidas con distintos disfraces: dioses mitológicos, personajes pastoriles, virtudes, alegorías de conceptos e ideas relativos a la ocasión celebrada. A veces sólo llegaba a ser un paseo por la ciudad adornados con telas vistosas, portando antorchas o hachas de cera y acompañados de músicos con tambores y trompetas. Las protagonizaban los diferentes grupos sociales: gremios, nobles del ayuntamiento, instituciones de la ciudad, vecinos de una nación determinada. Desfilaban siempre de noche, a pie o a caballo, por las calles y plazas formando algazara o deteniéndose en una representación parateatral.

En Sevilla tenemos noticias por primera vez en 1559 para celebrar la paz con Francia. Debía de existir este tipo de festejos antes, pues en el resto de España hay ejemplos ${ }^{16}$. En los eventos más señalados, las máscaras acompañaban a los carros alegóricos, a modo de tableaux vivants. Muy importantes fueron los que la ciudad de Sevilla realizó con motivo de la victoria de Lepanto y el nacimiento del príncipe Fernando, el nuevo heredero, en 1571-72. Las alegorías respondían a una triple fuente literaria y cultural: la medieval religiosa, la pastoril y la antigüedad clásica.

Las ciudades con río solían incluir entre sus festejos las diversiones en el agua. El Guadalquivir casi abraza con su cauce a Sevilla. El río forma parte de la vida cotidiana del sevillano, constituía su don y su azote, por donde venía el

13. GALLEGO, Julián, Visión y Símbolos en la pintura española del Siglo de oro. Madrid, 1984, pp. 125-126.

14. HUIZINGA, Johan, El Otoño de la Edad Media. Madrid, 1981, p. 180.

15. GUICHOT Y PARODY, Joaquín, Historia del Excelentísimo Ayuntamiento de la Ciudad de Sevilla. Sevilla, 1896, vol. I, apéndice $2^{\circ}$, pp. 352-355.

16. MARSDEN, C.A., o. c., p. 399. 
oro de América y las calamidades de las inundaciones periódicas. En este siglo se siguieron celebrando pruebas de competición y destreza. Una de ellas fue el "correr palios" (piezas de tejido de alto precio: seda, damasco, terciopelo o tafetán) en el río. No era más que una carrera de barcos hasta una meta donde se encontraba el premio. Esto mismo se hacía en tierra montando a caballo. También se podía colocar la pieza de tela en lo alto de un mástil ensebado que los marineros del puerto clavaban en la tierra. Los que intentaban subir resbalaban una y otra vez cayendo al suelo entre las carcajadas del público. Otras competiciones en el río eran la cucaña y las regatas que por primera vez se celebraron en 1519 con motivo de la elección del emperador Carlos $\mathrm{V}{ }^{17}$. El pueblo llano protagonizaba estos festejos.

También en el río, se llevaron a cabo espectáculos poco frecuentes en España. De hecho en Sevilla sólo conocemos un caso. Se trata de las naumaquias. La ocasión fue con la visita de la marquesa de Denia, esposa del valido real, en 1599. La marquesa presenció la contienda acuática desde la vecina Torre del Oro. Se enfrentaron las flotas de Sicilia al mando del general don Pedro de Leiva y la de Portugal del marqués de Santa Cruz.

Estas batallas simuladas se hacían también en tierra. Se construía un castillo ficticio y se representaba un asalto. Constituía un revivir las antiguas guerras de moros y cristianos (que perviven aún en pueblos de España). El castillo y la pelea se animaba por la vistosidad de los cohetes mientras las llamas lo consumían. Un caso parecido en Sevilla fue en las fiestas de la victoria de Lepanto en las que el castillo fue un dragón con fuegos de artificio en su interior, representaba a los turcos. Se enfrentaba a un guerrero que era don Juan de Austria.

Por último vamos a reseñar las "luminarias" y fuegos de artificio. Con el paso de los años tuvieron un lugar cada vez más destacado en la celebración. Las "luminarias" fue la forma más espontánea, sencilla, rápida, visible y generalizada de expresar la alegría por una fiesta o acontecimiento. Lógicamente se realizaban de noche en las zonas altas de la ciudad: campanarios de las iglesias, murallas, pináculos, fachadas de casas particulares y edificios oficiales. Se hacían con antorchas, hachas de cera, cazuelas o toneles con alquitrán, esparto y soga a los que se prendía fuego. El perfil urbano de la ciudad se recortaba entre el titilar de las luces.

Las luminarias ya se realizaban en siglos anteriores. En cambio los fuegos de artificio se generalizan con la pólvora en el siglo XVI y su utilización va en un aumento imparable. Se llega a auténticos espectáculos pirotécnicos con las llamadas "invenciones" que Varey piensa de origen italiano ${ }^{18}$. En Sevilla el lugar más común fue la torre de la catedral, la Giralda. Son muy frecuentes desde la segunda mitad del siglo XVI con dragones voladores, galeras colgantes, ruedas

17. GESTOSO Y PÉREZ; José, Curiosidades antiguas sevillanas, $2^{\mathrm{a}}$ serie. Sevilla, 1910, pp. 195-215. 18. VAREY, J.E., o. c., p. 631. 
de cohetes y castillos con figuras que se consumían entre las llamas. En 1526, a la entrada de Isabel de Portugal, se le ofrecieron cuatro dragones voladores vomitando fuego por la boca ${ }^{19}$. Espectáculos parecidos pero más complicados se hicieron con la visita de Felipe II en 1570 y la marquesa de Denia en 1599. En la fiesta anual de San Pedro desde mediados del siglo se ofrecían este tipo de diversiones con un castillo de figuras en la Giralda acompañado de música de tambores y trompetas.

Los festejos que hemos reseñado tuvieron gran frecuencia. He aquí un breve elenco de entre los que hemos podido documentar.

En 1506 se celebraron justas por la vuelta de Fernando el Católico a Castilla y por la fiesta del Corpus Christi. En 1507 más festejos por el regreso del rey desde Nápoles. En 1508, Fernando visita Sevilla y se alzaron trece arcos triunfales y las tradicionales diversiones populares. En 1516, la proclamación de la reina Juana y Carlos I. En 1519, la elección imperial de Carlos I. En 1522, el retorno del emperador a España. En 1525, la victoria de Pavía sobre los franceses. En 1526, la visita y bodas de Carlos V e Isabel de Portugal en la que se alzaron siete arcos triunfales y se celebraron festejos de toros y cañas, justas y torneos en los que intervino el propio emperador. En 1527 se preparaban las fiestas por el nacimiento del príncipe Felipe y se suspendieron por el "saco de Roma". En 1531, el nombramiento de cardenal al arzobispo de Sevilla. En 1532, la victoria contra los turcos en Viena. En 1545, la ciudad se enfervorizaba para celebrar el nacimiento del infante don Carlos pero se suspendieron los festejos por la muerte de la madre. En 1555, la boda de Felipe II con María Estuardo. En 1556, la subida al trono de Felipe II y la vuelta a España del emperador. En 1559, la paz con Francia. En 1562, la recuperación de la salud del infante Carlos tras un accidente. En 1570, la visita de Felipe II a la ciudad. Entre 1571 y 1572, la victoria de Lepanto y el nacimiento del príncipe Fernando. En 1575, se recibió solemnemente el Breviario Romano. En 1578, el nacimiento del futuro Felipe III. En 1580, la unión con Portugal. En 1582, la victoria del marqués de Santa Cruz en las Azores y la entrada del nuevo arzobispo don Rodrigo de Castro. En 1583, la vuelta a Castilla de Felipe II desde Portugal. En 1586, nace una nieta de Felipe II. En 1590, la elección de Urbano VII y Gregorio XIV. En 1592 la elección de Clemente VIII y de un sevillano como presidente de Castilla. En 1594, se celebraron justas por los regidores del cabildo de la ciudad. En 1598, la subida al trono de Felipe III. En 1599, la llegada de Margarita de Austria, sus bodas y la visita de la marquesa de Denia. A todo esto hay que añadir anualmente los toros y cañas en Santa Ana, Santas Justa y Rufina, San clemente, patronos de la ciudad, etc.

19. CARRIAZO Y ARROQUIA, Juan de Mata, "La Boda del Emperador", en Archivo Hispalense, $\mathrm{n}^{\circ}$ 93-94. Sevilla, 1959 , p. 86. 


\section{INFLUENCIA EN OCCIDENTE}

El Siglo de Oro español tenía un peso específico tan fuerte que desbordó sus fronteras y se dejó sentir en otras tierras. Si la tradición de fiestas de Borgoña influyó notablemente en Castilla, también las fiestas españolas tradicionales aparecen en lugares como Italia. Benedetto Croce en su libro La Spagna nella vita italiana durante la Rinascenza (Bari, 1922), atribuye las manías caballerescas a los españoles. De hecho se celebraron juegos de cañas en distintos puntos de la geografía italiana como en Nápoles en 1510, en Roma en 1519, en Bolonia en 1529 y de nuevo en Nápoles, con auténticos moros, en $1543^{20}$.

Pero es en América donde la influencia española es algo más. El injerto de lengua, creencias e instituciones, dio lugar a una nueva cultura en la que los festejos tradicionales ocupan el mismo puesto que en la península. No hay más que repasar los cronistas de Lima, como Suardo o Mugaburu, y comprobar que parecidos festejos se realizaban por idénticos motivos ${ }^{21}$. Un ejemplo elocuente es el conquistador de México, Hernán Cortés, organizando una máscara en Madrid, por la boda de la hija del secretario de Carlos V en $1541^{22}$. Es de suponer que en la fiesta americana la impronta andaluza sea mayor por el número superior de emigrantes andaluces. Incluso hay constancia de influencias directas al quererse imitar en Lima el modo de festejar el Corpus Christi como se hacía en Sevilla ${ }^{23}$. Lógicamente, América aportaría también facetas y matices propios. El papel de la fiesta como elemento aculturador y factor aglutinante en América española aún se encuentra por desvelar.

\section{EL ARTE Y LA FIESTA}

Dijimos al comienzo que la fiesta es especialmente interesante para los historiadores del arte porque la fiesta y el arte van de la mano. La fiesta se expresa por y en el arte. El arte aspira a la eternidad, y de ahí que el mejor modo de celebrar una fiesta sea sublimarla en la belleza de las formas ${ }^{24}$.

En las fiestas del renacimiento y el barroco, los sentidos desempeñan un papel fundamental, pero será la vista especialmente el factor dominante en la celebración. A través de ellos penetran las ideas de modo sugerente y eficaz.

20. MARSDEN, C.A., o. c., p. 394. GALLEGO, J., o. c., pp. 126-127.

21. SUARDO, Juan Antonio, Diario de Lima (1629-1639). Lima, 1936. MUGABURU, José de, Diario de Lima (1640-1694). LIma, 1935. COSSIO, J. M., o. c., vol. IV, pp. 169 y ss.

22. KENISTON, Hayward, Francisco de los Cobos, Secretario de Carlos V. Madrid, 1980, pp. 223-224.

23. LOHMANN VILLENA, Guillermo, El Arte Dramático en Lima durante el Virreinato. Madrid, 1945, pp. 6 y ss. Ver también mi libro Arte festivo en Lima virreinal (Siglos XVI y XVII). Sevilla, 1992, pp. 204 y ss.

24. PIEPER, Josef, Una teoría de la fiesta. Madrid, 1974, p. 67. 
Si bien en los festejos que hemos visto el arte no pasa de mera decoración escenográfica, más o menos suntuosa según la ocasión, a excepción de los carros alegóricos, sí había una transformación del espacio cotidiano en lugar festivo ${ }^{25}$. Se podría hablar de un urbanismo utópico como en las entradas reales con arquitecturas efímeras ${ }^{26}$, en el que las justas y torneos transforman la calle y los toros y cañas la plaza. La ciudad monótona se convertía en ciudad divertida. Los toros, por ejemplo, son una constante en la vida española y por eso un tema frecuente en la pintura ${ }^{27}$.

En Sevilla durante el siglo XV se llevaron a cabo estos regocijos en diferentes lugares, pero desde el siglo XVI es la plaza de San Francisco el corazón festivo de la ciudad. En ella se alzaban los tablados y gradas para que las autoridades y el pueblo presenciaran el festejo. Se adomaban con flores, terciopelos, damascos y escudos. También fue bastante utilizado el lugar de las Gradas.

\section{FUNCIONES DE LA FIESTA}

Tras este frenesí de diversiones y regocijos en un pueblo que sentía la alegría de vivir, cabe preguntarse por las causas profundas de la variedad, persistencia e intensidad de la fiesta en España hasta hoy en día, especialmente en Andalucía.

La fiesta tiene varias funciones en la sociedad española como apunta Bennassar ${ }^{28}$. En ellas se cubre la necesidad natural del hombre de la comunicación colectiva. Por esta razón los pueblos con un fuerte espíritu festivo son más humanos y sociables. Las fiestas que hemos enumerado servían para contentar y divertir al pueblo, más aún por las calamidades frecuentes: sequías, hambres, pestes, etc. Son ocasión de descanso y solaz para el cuerpo y el espíritu. Son diversión y entretenimiento, el respiro relajante de los esfuerzos de la vida diaria. En las fiestas se rendían honores a las autoridades reales y religiosas. Exaltan dogmas con fines pedagógicos. Al mismo tiempo tienen un factor de unión y homogeneización social al participar todos los estamentos del mismo festejo. En la fiesta hispánica se produce ese carácter tan específico de la unión del rey con su pueblo. Por otro lado en esas mismas celebraciones se reafirman las jerarquías sociales y el poder. Son momentos en los que se lucen las riquezas y habilidades.

La fiesta en su sentido más genuino es una exaltación de la vida, de la existencia y del ser, incluso tratándose de la fiesta luctuosa ${ }^{29}$. Con la fiesta, los

25. CHASTEL, André, "Le lieu de la fête", en Les Fêtes..., vol. I, p. 420.

26. LLEO CAÑAL, Vicente, Nueva Roma..., p. 167.

27. MORALES, José Luis, Los Toros en el Arte. Madrid, 1986. AMORÓS, Andrés, Toros y Cultura. Madrid, 1986.

28. BENNASSAR, B., Los Españoles..., pp. 148-149. BONET CORREA, Antonio, "La fiesta como práctica del poder", en El arte efímero en el Mundo Hispánico. México, 1983, pp. 43-78.

29. PIEPER, J., o. c., p. 38. 
elementos que componen la jornada como el trabajo, la previsión y el ahorro, desaparecen. Se hace una parada en la monotonía diaria, se suspenden las coordenadas del tiempo y del espacio cotidianos y se da paso a la afirmación del instante, corto pero intenso. Es un anhelo de la felicidad continua. El tiempo festivo es la eternidad. La fiesta es la poesía en la prosa diaria.

En esta época toda celebración tiene una doble cara. La faz religiosa con misa, sermón, procesión y la oración en sus diversos matices (petición, desagravio, acción de gracias). La alegría interna desbordaba y se materializaba en manifestaciones externas con los festejos citados que son la faz profana. Es decir todo se insertaba en una visión trascendente del hombre y el mundo. Bennassar opina que una de las razones íntimas de la adhesión de España a la fiesta es la protección del catolicismo a esta. Hay que matizar, pues el catolicismo no apoya la fiesta como táctica en principio, sino en coherencia con su propio credo. El triunfo de la vida sobre la muerte, el triunfo total y definitivo de Cristo sobre el mal, y por eso mismo motivo de júbilo continuo. España es un pueblo de profunda religiosidad y por tanto tremendamente festivo. Un pueblo religioso, sea cual sea la creencia, es un pueblo necesariamente dado a la fiesta. En ella, el rito y la ceremonia envuelven la vida diaria elevando la contingencia de cada momento a la esfera de la eternidad. 